This is the post peer-review accepted manuscript of:

A. N. Tallarico et al. "Threshold Voltage Instability in GaN HEMTs with p-type Gate: Mg Doping Compensation " in IEEE Electron Device Letters, vol. 40, no. 4, pp. 518521, Apr. 2019.

The published version is available online at:

https://ieeexplore.ieee.org/stamp/stamp.jsp?tp=\&arnumber $=8636498$

(C) 2019 IEEE. Personal use of this material is permitted. Permission from IEEE must be obtained for all other uses, in any current or future media, including reprinting/republishing this material for advertising or promotional purposes, creating new collective works, for resale or redistribution to servers or lists, or reuse of any copyrighted component of this work in other works.

\title{
Threshold Voltage Instability in GaN HEMTs with p-type Gate: Mg Doping Compensation
} Andrea Natale Tallarico, Steve Stoffels, Niels Posthuma, Stefaan Decoutere, Enrico Sangiorgi, Fellow, IEEE, and Claudio Fiegna

\begin{abstract}
In this letter, we present an analysis of the threshold voltage shift induced by positive bias temperature instability stress in GaN-based power HEMTs with p-type gate, controlled by a Schottky metal/p-GaN junction. In particular, we show the positive effect of the magnesium compensation process in the $\mathrm{p}$-GaN layer on the long-term threshold voltage instability. When a relatively high positive gate bias is applied (Schottky junction reverse-biased), holes generated by impact ionization in the high-field depleted pGaN region are accelerated towards the AlGaN layer, where, combined with the high temperature effects, create defects in the AlGaN or at its interface with p-GaN, causing a long-term positive threshold voltage shift. A process variation in the $\mathbf{p - G a N}$ layer is introduced which promotes a wider depletion region near the Schottky interface with the metal, lowering the electric field and reducing the generation of holes due to impact ionization. As a result, the long-term threshold voltage instability is improved without altering the
\end{abstract}

This paragraph of the first footnote will contain the date on which you submitted your paper for review.

A. N. Tallarico, E. Sangiorgi, and C. Fiegna are with the Advanced Research Center on Electronic System, Department of Electrical, Electronic, and Information Engineering, University of Bologna, via Pavese 50, 47522, Cesena, Italy (e-mail: a.tallarico@unibo.it; enrico.sangiorgi@unibo.it; claudio.fiegna@unibo.it).

S. Stoffels, N. Posthuma, and S. Decoutere are with imec vzw, Kapeldreef 75, B-3001, Leuven, Belgium (e-mail: Steve.Stoffels@imec.be; Niels.Posthuma@imec.be; Stefaan.Decoutere@imec.be).
DC transistor parameters such as threshold voltage, transconductance, subthreshold slope, etc.

Index Terms - Positive bias temperature instability, threshold voltage instability, breakdown voltage, magnesium compensation process, doping concentration, p-type GaN gate, power HEMTs.

\section{INTRODUCTION}

$\mathrm{R}$ ELIABILITY, together with performance and cost, is among the most important features required for the adoption of $\mathrm{GaN}$ power devices in areas of increasing interest such as renewable energy, electric vehicles, data centers, industrial motors and consumer electronics $[1,2]$. To date, a broad range of suppliers such as EPC, Infineon, Transphorm, Panasonic, GaN Systems, Dialog and Navitas produce GaN-based devices, characterized by different combinations of process and design options [3], to address several different power applications. Overall, the power electronics market strongly prefers enhancement mode transistors for reasons related to cost, size, safety and power consumption $[4,5]$.

CMOS-fab compatible power HEMTs with a p-type gate, grown on $200 \mathrm{~mm} \mathrm{Si}$-substrates [6], is among the most interesting solutions to achieve normally-off device operation, offering a good trade-off between reliability 
and cost [7].

The impact of the gate metallization and, in general, of gate design parameters on the performance of $\mathrm{p}-\mathrm{GaN}$ HEMTs has been extensively investigated in [8-10].

Several reliability studies focused on the p-GaN gate have been carried out over the last few years [11-25]. First, we proposed the equivalent circuit of the p-GaN gate, consisting of two back to back connected junctions (i.e. a Schottky and PiN diode formed by metal $/ \mathrm{p}-\mathrm{GaN}$ and $\mathrm{p}-\mathrm{GaN} / \mathrm{AlGaN} / \mathrm{GaN}$, respectively), and an empirical relationship between gate leakage and gate time-to-failure (TTF) guiding device optimization [14]. Then, in agreement with [14], a temperature dependent TTF, with an activation energy of $0.48-0.50 \mathrm{eV}$, has been reported in [15]. Finally, we demonstrated that the characteristics of the percolation path, leading to time dependent gate breakdown, significantly depend on the concentration of magnesium $(\mathrm{Mg})$ in the $\mathrm{p}-\mathrm{GaN}$ layer and on the aluminum (Al) concentration in the barrier layer [16, 17].

In addition to the failure due to gate breakdown events, another important mechanism limiting the device reliability is the threshold voltage $\left(\mathrm{V}_{\mathrm{TH}}\right)$ instability during high temperature gate bias (HTGB) tests, also named positive bias temperature instability (PBTI) stress [18-25]. In particular, in [18] we investigated the role of the aluminum concentration in the AlGaN barrier on the $\mathrm{V}_{\text {тн }}$ instability occurring during PBTI stress, proposing the presence of two competing trapping mechanisms: i) holes filling of pre-existing defects located in the $\mathrm{AlGaN}$, causing a short-term negative and recoverable $\mathrm{V}_{\mathrm{TH}}$ shift; ii) creation of defects filled with electrons, inducing a positive and permanent (or slowly recoverable) $\mathrm{V}_{\mathrm{TH}}$ degradation. The latter mechanism, occurring at large positive gate biases, has been attributed to holes generated by impact ionization in the high-field depleted $\mathrm{p}-\mathrm{GaN}$ region and accelerated towards the AlGaN layer [18].

The results of experimental analysis reported by several authors [19-24], based on constant voltage and/or pulsed/transient stress, seem to confirm the presence of two mechanisms occurring in the p-GaN/AlGaN stack, i.e. holes injection and electrons trapping, although the details of temperature and gate bias dependence are related to the specific stress technique and device process adopted in each study [18-24].

Finally, Tajalli et al. recently demonstrated the suppression of the negative $\mathrm{V}_{\mathrm{TH}}$ shift by optimizing the etching and passivation of the p-GaN sidewalls [25].

In this letter, which is complementary to [18], we further validate the theory proposed in our previous study and propose a possible solution aimed at reducing the long-term positive $\mathrm{V}_{\mathrm{TH}}$ degradation occurring during PBTI stress. It consists of a magnesium compensation process implemented in the $\mathrm{p}-\mathrm{GaN}$ layer in the vicinity of the gate metal interface.

\section{Devices Characteristics}

Enhancement-mode GaN-HEMTs with p-type gate, fabricated at imec on $200 \mathrm{~mm} \mathrm{Si}$-substrate using an Aufree CMOS-compatible process flow [26] are considered in this study. The top layers, grown on a super lattice buffer, consist of a $400 \mathrm{~nm}$-thick GaN channel, a 12.5 nm-thick AlGaN barrier with $22.5 \%$ aluminum concentration, an $80 \mathrm{~nm}$-thick p-type GaN layer doped with magnesium and a $30 \mathrm{~nm}$-thick TiN metal.

The devices under test (DUT) feature a symmetric structure with a gate length $\left(\mathrm{L}_{\mathrm{G}}\right)$ of $0.8 \mu \mathrm{m}$, gatesource/drain spacing length $\left(\mathrm{L}_{\mathrm{GD}}=\mathrm{L}_{\mathrm{GS}}\right)$ of $0.85 \mu \mathrm{m}$, and gate width of 100 and $500 \mu \mathrm{m}$. The adoption of different gate widths is motivated by the limited availability of the devices on-wafer. However, it is worth noting that different gate widths have been adopted only for the evaluation of the threshold voltage instability during PBTI stress, because, as well known for CMOS technology, and confirmed in Fig. 4 for p-GaN HEMTs, the underlying mechanisms are independent of gate area.

Two devices groups, named process 1 and 2, have been adopted. It is worth noting that the devices of these two groups are identical concerning materials, dimensions, etching, passivation, etc., except for the doping profile of the p-GaN layer. In particular, process 2 features a $\mathrm{Mg}$ compensation option, aimed at reducing the active Pdoping concentration close to Schottky interface with the metal, thus widening the depletion region and reducing the maximum electric field in the p-GaN layer, while limiting the impact on threshold voltage [27].

As a matter of fact, on one hand the controlled $\mathrm{Mg}$ compensation process step has no impact on the transfer characteristics of the transistors in both sub-threshold and linear regions, as shown in Fig. 1. On the other hand, by observing Fig. 2, a clear impact can be observed on the gate leakage characteristics measured at different temperatures. As expected, independently of the temperature, process 2 shows a lower gate leakage at relatively high gate biases (solid lines). In particular, the reduction of the active doping concentration close to the Schottky junction, promotes a wider depletion region when a positive bias is applied on the gate, and the Schottky metal/p-GaN junction is reverse biased. As a result, for the same gate voltage $\left(\mathrm{V}_{\mathrm{GS}}\right)$, the electric field is lower in process 2 and a lower gate leakage is attained for $\mathrm{V}_{\mathrm{GS}}$ larger than $2 \mathrm{~V}$ (Fig. 2), i.e. the bias condition for which the Schottky barrier is limiting the leakage, as discussed in [16]. Moreover, in [16] it has been also shown that the gate leakage for $\mathrm{V}_{\mathrm{GS}}$ lower than $\approx 1.5 \mathrm{~V}$ is mainly dominated by the $\mathrm{p}-\mathrm{GaN} / \mathrm{AlGaN} / \mathrm{GaN}$ diode. Since the latter, is exactly the same for the two processes, the same gate leakage is attained for $\mathrm{V}_{\mathrm{GS}}$ lower than $\approx 1.5$ $\mathrm{V}$ (Fig. 2), without any modification of sub-threshold region (Fig. 1). This confirms that the adopted Mgcompensation option only impacts the Schottky interface region while the $\mathrm{p}-\mathrm{GaN} / \mathrm{AlGaN} / \mathrm{GaN}$ diode is unaffected.

Fig. 3 shows the gate breakdown voltage (BV) extracted from the ramp voltage tests in Fig. 2. Two features can be noticed: i) a positive temperature 
dependence occurs only in process 1. This behavior is ascribed to a dominant role of impact ionization as discussed in [18]. The lower the temperature, the higher the impact ionization generation, the lower the breakdown voltage of the metal/p-GaN Schottky junction. Furthermore, the higher impact ionization occurring at lower temperatures, speeds up the creation of defects in the depleted region of the Schottky junction, thus accelerating device failure as reported in [18]; ii) BV is temperature independent in process 2 and its mean value (exponential fitting in Fig. 3) is close to the highest BV mean value attained at $150{ }^{\circ} \mathrm{C}$ for process 1 , confirming the reduced role of impact ionization. These results confirm the positive impact of increasing the depletion length and decreasing the electric field though the $\mathrm{Mg}$ compensation option.

\section{Threshold Voltage Instability}

Fig. 4 shows the threshold voltage shift as a function of gate stress voltage and temperature on devices featuring different $\mathrm{p}-\mathrm{GaN}$ processes.

The trapping mechanisms behind the dynamic of the $\mathrm{V}_{\mathrm{TH}}$ instability has been discussed and detailed in [18], by analyzing devices with different processes. In particular, the initial temperature independent (or very small dependent) negative $\Delta \mathrm{V}_{\mathrm{TH}}$ is ascribed to filling by holes of pre-existing defects, located in the AlGaN barrier, through temperature independent elastic tunneling. The positive $\Delta \mathrm{V}_{\mathrm{TH}}$ occurring at long stress times is explained by thermally activated creation of defects by hot holes. Because of the impact ionization mechanism occurring in the high-field depleted region of the $\mathrm{p}$-GaN layer close to metal/p-GaN interface, holes can be generated and then accelerated in the valence band toward the AlGaN barrier where they release their energy to the lattice and combined with the phonon energy (high temperature), can create deep defects in the AlGaN barrier or at the p$\mathrm{GaN} / \mathrm{AlGaN}$ interface. In particular, by increasing the temperature, a lower hole kinetic energy is needed to create/activate a defect. Hence, although hot-hole energy is lower at higher temperatures, due to higher energy dissipation through hole-phonon scattering, the released energy can be still sufficient to create a defect. Once defects are created, dependently on their energy position inside the bandgap, they can be filled by electrons coming from the $2 \mathrm{DEG}$ or from the AlGaN valence band, causing a positive $\Delta \mathrm{V}_{\mathrm{TH}}$.

The relevance of impact ionization in process 1 devices is confirmed by the positive temperature dependence of the breakdown voltage shown in Fig. 3 (process 1). Moreover, impact ionization at lower gate voltages (from $\approx 6 \mathrm{~V}$ to $\mathrm{BV}$ ) can be confirmed by roughly estimating the electric field in the case of an abrupt one-dimensional Schottky junction (metal/p-GaN). In particular, thanks to the back-to-back diode model proposed in [16], where the voltage drop across the Schottky junction is calculated as a function of the gate bias, a maximum electric field of the same order of magnitude of the GaN critical field (3.3 $\mathrm{MV} / \mathrm{cm}$ ) is estimated for gate biases higher than $\approx 6 \mathrm{~V}$, hence confirming the presence of impact ionization.

As improving solution, process 2 reduces the active $\mathrm{Mg}$ concentration near the Schottky interface, promoting a wider depletion region and a lower electric field when a positive gate bias is applied. The lower the electric field, the lower the amount of holes generated by impact ionization and consequently the lower is the positive $\Delta \mathrm{V}_{\mathrm{TH}}$ due to deep defects creation (Fig. 4, process 2).

\section{Conclusion}

In this letter, the effect of the magnesium doping compensation on the threshold voltage instability induced by PBTI stress has been investigated in e-mode GaN-on$\mathrm{Si}$ HEMTs. The theory behind the positive $\mathrm{V}_{\mathrm{TH}}$ drift proposed in [18] has been further validated and, based on it, a viable process solution aimed at reducing the longterm positive $\mathrm{V}_{\mathrm{TH}}$ shift has been proposed. In addition to [18], where the role of the aluminum concentration in the AlGaN barrier on the $\mathrm{V}_{\mathrm{TH}}$ instability was investigated, the role of the active magnesium profile in the p-GaN layer has been analyzed in this letter. In particular, by reducing the active doping $(\mathrm{Mg})$ concentration in the $\mathrm{p}-\mathrm{GaN}$ layer, only relatively close to metal interface, a more robust device to $\mathrm{V}_{\mathrm{TH}}$ instability is attained without altering import transistor parameters such as threshold voltage, trans-conductance and sub-threshold slope.

\section{REFERENCES}

V. Power GaN 2017: Epitaxy, Devices, Applications, and Technology Trends 2017 report, Yole Développement, Oct. 2017. VI. M. Meneghini, I. Rossetto, C. De Santi, F. Rampazzo, A. Tajalli, A. Barbato, M. Ruzzarin, M. Borga, E. Canato, E. Zanoni, G. Gaudenzio, "Reliability and failure analysis in power GaNHEMTs: an overview", IEEE International Reliability Physics Symposium (IRPS), pp. 3B-2.1-3B-2.8, Monterey, CA, USA, Apr. 2017, DOI: 10.1109/IRPS.2017.7936282.

VII. H. Amano et al., "The $2018 \mathrm{GaN}$ power electronics roadmap", Journal of Physics D: Applied Physics", vol. 51, no. 16, Mar. 2018, https://doi.org/10.1088/1361-6463/aaaf9d.

VIII. J. Millan, P. Godignon, X. Perpina, A. Perez-Tomas, and J. Rebollo, "A survey of wide bandgap power semiconductor devices," IEEE Trans. Power Electron., vol. 29, no. 5, pp. 21552163, May 2014, DOI: 10.1109/TPEL.2013.2268900.

IX. K. J. Chen, O. Haberlen, A. Lidow, C. L. Tsai, T. Ueda, Y. Uemoto, Y. Wu, "GaN-on-Si Power Technology: Devices and Applications," IEEE Trans. Electron Devices, vol. 64, no. 3, pp. 779-796, Mar. 2017, DOI: 10.1109/TED.2017.2657579.

X. N. E. Posthuma, S. You, S. Stoffels, D. Wellekens, H. Liang, M. Zhao, B. De Jaeger, K. Geens, N. Ronchi, S. Decoutere, P. Moens, A. Banerjee, H. Ziad, M. Tack, “An industry-ready 200 $\mathrm{mm}$ p-GaN E-mode GaN-on-Si power technology", IEEE International Symposium on Power Semiconductor Devices and ICS (ISPSD), pp. 284-287, Chicago, IL, USA, May 2018, DOI: 10.1109/ISPSD.2018.8393658.

XI. D. Marcon, Y. N. Saripalli, S. Decoutere, "200mm GaN-on-Si epitaxy and e-mode device technology," IEEE International Electron Devices Meeting (IEDM), pp. 16.2.1-16.2.4, Washington, DC, Dec. 2015, DOI: 10.1109/IEDM.2015.7409709.

XII. I. Hwang, J. Kim, H. S. Choi, H. Choi, J. Lee, K. Y. Kim, J. B. Park, J. C. Lee, J. Ha, J. Oh, J. Shin, U-In Chung, "p-GaN gate HEMTs with tungsten gate metal for high threshold voltage and 
low gate current", IEEE Electron Device Lett., vol. 34, no. 2, Feb. 2013, 10.1109/LED.2012.2230312.

XIII. F. Lee, L. Y. Su, C. H. Wang, Y. R. Wu, J. Huang, "Impact of gate metal on the performance of $\mathrm{p}-\mathrm{GaN} / \mathrm{AlGaN} / \mathrm{GaN}$ high electron mobility transistors," IEEE Electron Device Lett., vol. 36, no. 3, Mar. 2015, 10.1109/LED.2015.2395454.

XIV. L. Efthymiou, G. Longombardi, G. Camuso, T. Chien, M. Chen, F. Udrea, "On the physical operation and optimization of the p-GaN gate in normally-off GaN HEMT devices", Applied Physics Letters, vol. 110, no. 12, pp. 1-5, Mar. 2017, https://doi.org/10.1063/1.4978690.

XV. M. Tapajina, O. Hilt, E. B. Treidel, J. Wurfl, and J. Kuzmik, "Gate Reliability Investigation in Normally-Off p-Type-GaN Cap/AlGaN/GaN HEMTs Under Forward Bias Stress," IEEE Electron Device Lett., vol. 37, no. 4, Apr. 2016, DOI: 10.1109/LED.2016.2535133.

XVI. I. Rossetto, M. Meneghini, O. Hilt, E. B. Treidel, C. De Santi, S. Dalcanale, J. Wuerfl, E. Zanoni, and G. Meneghesso, "Time-Dependent Failure of GaN-on-Si Power HEMTs with p-GaN Gate," IEEE Trans. Electron Devices, Vol. 63, No. 6, pp. 23342339, Jun. 2016, DOI: 10.1109/TED.2016.2553721.

XVII. I. Rossetto, M. Meneghini, R. Silvestri, S. Dalcanale, E. Zanoni, G. Meneghesso, O. Hilt, E. B. Treidel, J. Wuerfl, "Experimental demonstration of Weibull distributed failure in $\mathrm{p}$ type GaN high electron mobility transistors under high forward bias stress," IEEE International Symposium on Power Semiconductor Devices and ICs (ISPSD), pp. 35-38, Prague, Czech Republic, 2016, DOI: 10.1109/ISPSD.2016.7520771.

XVIII. A. N. Tallarico, S. Stoffels, P. Magnone, N. Posthuma, E. Sangiorgi, S. Decoutere, C. Fiegna, "Investigation of the p-GaN Gate Breakdown in Forward-Biased GaN-Based Power HEMTs," IEEE Electron Device Lett., vol. 38, no. 1, pp. 99-102, 2017, DOI: 10.1109/LED.2016.2631640.

XIX. M. Meneghini, I. Rossetto, M. Borga, E. Canato, C. De Santi, F. Rampazzo, G. Meneghesso, E. Zanoni, S. Stoffels, M. Van Hove, N. Posthuma, S. Decoutere, "Degradation of GaNHEMTs with p-GaN Gate: Dependence on Temperature and on Geometry," IEEE International Reliability Physics Symposium (IRPS), pp. 4B5.1-4B5.5, Monterey, CA, USA, 2017, DOI: 10.1109/IRPS.2017.7936311.

XX. S. Stoffels, B. Bakeroot, T. L. Wu, D. Marcon, N. E. Posthuma, S. Decoutere, A. N. Tallarico, C. Fiegna, "Failure mode for $\mathrm{p}-\mathrm{GaN}$ gates under forward gate stress with varying $\mathrm{Mg}$ concentration, " IEEE International Reliability Physics Symposium (IRPS), pp. 4B4.1-4B4.9, Monterey, CA, USA, Apr. 2017, DOI: 10.1109/IRPS.2017.7936310.

XXI. I. Rossetto, M. Meneghini, E. Canato, M. Barbato, S. Stoffels, N. Posthuma, S. Decoutere, A. N. Tallarico, G. Meneghesso, E. Zanoni, "Field- and current-driven degradation of $\mathrm{GaN}-$ based power HEMTs with p-GaN gate: Dependence on $\mathrm{Mg}$ doping level", Microelectronics Reliability, vol. 76-77, pp. 298303, Sept. 2017, DOI: 10.1016/j.microrel.2017.06.061.

XXII. A. N. Tallarico, S. Stoffels, N. Posthuma, P. Magnone, D. Marcon, S. Decoutere, E. Sangiorgi, C. Fiegna, "PBTI in GaN-
HEMTs with p-type gate: Role of the aluminum content on $\Delta \mathrm{V}_{\mathrm{TH}}$ and underlying degradation mechanisms", IEEE Trans. Electron Devices, vol. 65 , no. 1 , pp. 38-44, Jan. 2018, DOI: 10.1109/TED.2017.2769167.

XXIII.L. Sayadi, G. Iannaccone, S. Sicre, O. Haberlen, G. Curatola, "Threshold voltage instability in $\mathrm{p}-\mathrm{GaN} \mathrm{AlGaN} / \mathrm{GaN}$ HFETs", IEEE Trans. Electron Devices, vol. 65, no. 6, pp. 24542460, Jun. 2018, DOI: 10.1109/TED.2018.2828702.

XXIV.M. Ruzzarin, M. Meneghini, A. Barbato, V. Padovan, O. Haeberlen, M. Silvestri, T. Detzel, G. Meneghesso, E. Zanoni, "Degradation Mechanisms of GaN HEMTs with p-type gate under forward gate bias overstress", IEEE Trans. Electron Devices, vol. 65, no. 7, pp. 2778-2783, Jul. 2018, DOI: 10.1109/TED.2018.2836460.

XXV. X. Tiang, B. Li, H. A. Moghadam, P. Tanner, J. Han, S. Dimitrijev, "Mechanism of threshold voltage shift in p-GaN gate AlGaN/GaN transistors", IEEE Electron Device Lett., vol. 39, no. 8, pp. 1145-1148, Aug. 2018, DOI: 10.1109/LED.2018.2847669.

XXVI.Y. Shi, Q. Zhou, Q. Cheng, P. Wei, L. Zhu, D. Wei, A. Zhang, W. Chen, B. Zhang, "Bidirectional threshold voltage shift and gate leakage in $650 \mathrm{~V} \mathrm{p}-\mathrm{GaN}$ AlGaN/GaN HEMTs: The role of electron-trapping and hole-injection", IEEE International Symposium on Power Semiconductor Devices and ICs (ISPSD), pp. 96-99, Chicago, USA, May 2018, DOI: 10.1109/ISPSD.2018.8393611.

XXVII. J. He, G. Tang, K. J. Chen, "V $\mathrm{V}_{\text {тн }}$ instability of p-GaN gate HEMTs under static and dynamic gate stress", IEEE Electron Device Lett., vol. 39, no. 10, pp. 1576-1579, Oct. 2018, DOI: 10.1109/LED.2018.2867938.

XXVIII. L. Sayadi, G. Iannaccone, S. Sicre, S. Lavanga, G. Fiori, O. Haberlen, G. Curatola, "Charge injection in normally-off p$\mathrm{GaN}$ gate $\mathrm{AlGaN} / \mathrm{GaN}-$ on-Si HFETs", IEEE European Solid-State Device Research Conference (ESSDERC), pp. 18-21, Dresden, Germany, Sep. 2018, DOI: 10.1109/ESSDERC.2018.8486899. XXIX.A. Tajalli, E. Canato, A. Nardo, M. Meneghini, A. Stockman, P. Moens, E. Zanoni, G. Meneghesso, "Impact of sidewall etching on the dynamic performance of GaN-on-Si Emode transistors", Microelectronics Reliability, vol. 88-90, pp. 572-576, Sep. 2018, https://doi.org/10.1016/j.microrel.2018.06.037.

XXX. N. E. Posthuma, S. You, H. Liang, N. Ronchi, X. Kang, D. Wellekens, Y. N. Saripalli, S. Decoutere, "Impact of Mg outdiffusion and activation on the p-GaN gate HEMT device performance", IEEE International Symposium on Power Semiconductor Devices and ICs (ISPSD), pp. 95-98, Prague, Czech Republic, 2016, DOI: 10.1109/ISPSD.2016.7520786.

XXXI.B. Bakeroot, A. Stockman, N. Posthuma, S. Stoffels, S. Decoutere, "Analytical Model for the Threshold Voltage of p(Al)GaN High-Electron-Mobility Transistors", IEEE Trans. Electron Devices, vol. 65, no. 1, pp. 79-86, Jan. 2018, DOI: 10.1109/TED.2017.2773269. 